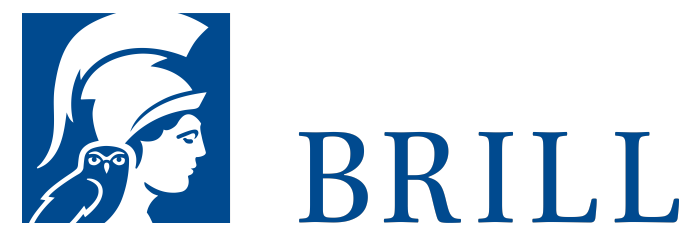

\title{
Richtig und doch falsch?
}

Der wahrheits- und Rechtfertigungsbegriff des metaethischen Relativismus

Author: Sebastian Muders

Welche Wahlmöglichkeiten haben Vertreter des metaethischen Relativismus hinsichtlich des Wahrheits- und Rechtfertigungsbegriffs, den sie für ihre Position in Anspruch nehmen? Und wie wirkt sich ihre Entscheidung auf die Plausibilität dieser Theorie aus? Anhand des bestehenden Angebots prominenter Wahrheits- und Rechtfertigungskonzeptionen, so der erste Teil der in diesem Buch vertretenen Antwort, ergibt sich für den Verfechter einer relativistischen Position zunächst eine breitere Auswahl als gemeinhin angenommen. Betrachtet man jedoch für den zweiten Teil der Ausgangsfrage die konkrete Verwendung dieser Wahrheits- und Rechtfertigungsbegriffe in führenden metaethisch-relativistischen Theorien, fällt auf, dass die an sie herangetragenen Anforderungen für sie aufgrund anderweitiger theorieinterner Entscheidungen umso schwieriger einzuhalten sind, je puristischer die Positionen auftreten. Varianten des Relativismus, die sich stärker zu ihren realistischen/objektivistischen Kontrahenten hin orientieren, können diese Anforderungen besser integrieren; dafür entstehen hier Spannungen zu den verbleibenden relativistisch geprägten Elementen dieser Theorien

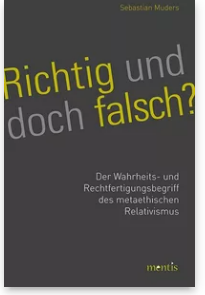

Pages: 481 Seiten

Language:

German

Subjects:

General, Philosophy

Publisher: Brill | mentis

E-Book (PDF)

Released online: 21 Sep 2015

ISBN: 978-395743-896-6 List price Paperback Publication date: 21 Sep 2015 ISBN: 978-395743-017-5 List price 
For more information see brill.com

Order information: Order online at brill.com +44330 333 0049 | customerservices@brill.com Submission information: brill.com/authors

Titles published by Brill | Fink, Brill | mentis or Brill | Schöningh: +49(o)715413279216| brill@brocom.de 